\title{
Interior Design Styles and Socio-demographic Characteristics in Egypt: From the concept of Zeitgeist
}

\author{
Rasha Mahmoud Ali El-Zeiny * \\ Faculty of Fine Arts, Minia 61519, Egypt
}

\begin{abstract}
Interior design plays an important role in reflecting the social and cultural environments of countries and showing the characteristics of the age. The previous literature has suggested that people's preferences for interior design styles are influenced by social distinctions, based on education level and age. In this study, we have argued more precisely socio - demographic factors (gender, age, income, major and city) that affect the Egyptians' preferences for interior design styles, and have discussed to what extent do the people preferences reflect Zeitgeist in Egypt. The findings supported the idea that socio-demographic factors can explain people's design preferences.
\end{abstract}

(C) 2016. The Authors. Published for AMER ABRA by e-International Publishing House, Ltd., UK. Peer-review under responsibility of AMER (Association of Malaysian Environment-Behaviour Researchers), ABRA (Association of Behavioural Researchers on Asians) and cE-Bs (Centre for Environment-Behaviour Studies, Faculty of Architecture, Planning \& Surveying, Universiti Teknologi MARA, Malaysia.

Keywords: Interior design; socio-demographic; Zeitgeist; styles

\section{Introduction}

Interior design plays an important role in reflecting the social and cultural environments of countries and showing the characteristics of the age. Zeitgeist (spirit of the age) is the intellectual fashion or dominant school of thought that typifies and influences the culture of a particular period. For example, Zeitgeist of modernism typified and influenced architecture, art, and fashion during much of the 20th century. The concept of Zeitgeist may be problematic as a tool for analysis of periods that are socially or culturally diverse like nowadays, there are no studies discussed the relation between socio-demographic factors and the styles' preferences in interior design from Zeitgeist point of view.

The previous literature has suggested that people's preferences for interior design styles are influenced by social distinctions, based on education level and age bracket, In this study, we have argued more precisely Socio - demographic factors (gender, age, income, major and city) that affect the Egyptians' preferences for interior design styles, and have discussed to what extent

\footnotetext{
* Corresponding author. Tel.: +0-000-000-0000

E-mail address: rasha_elzeiny@yahoo.com
}

(C) 2016. The Authors. Published for AMER ABRA by e-International Publishing House, Ltd., UK. Peer-review under responsibility of AMER (Association of Malaysian Environment-Behaviour Researchers), ABRA (Association of Behavioural Researchers on Asians) and cE-Bs (Centre for EnvironmentBehaviour Studies, Faculty of Architecture, Planning \& Surveying, Universiti Teknologi MARA, Malaysia.

DOl: http://dx.doi.org/10.21834/e-bpj.v1i1.224 
do the people preferences reflect Zeitgeist in Egypt. In the context of Egypt, this is a relatively new topic, and there aren't any studies in the field of interior design.

\section{Literature Review}

\subsection{Socio-demographic characteristics and interior design preferences}

Socio-demographic factors such as age, gender, household structure and income level all relate to the design, meaning and use of home interiors. For example, older house dwellers do not use as much new technology as that found in younger people's homes. Further, traditional values may determine that the kitchen is viewed as the woman's space, and design decisions here may reflect predominantly her values (Lawrence, 1987). As Eleb-Vidal has suggested, the interior of the home enables people to express themselves in terms of their personal and group identities and this could be accomplished through the interior design of the home and the personal possessions in it (Eleb-Vidal, 1983).

Hubbard claimed that education and social position influence how someone perceives an environment (Hubbard, 1996). Wilson and Mackenzie showed photographs of domestic interiors to 36 participants and asked them to classify those images regarding the characteristics of their owners (Wilson and Mackenzie, 2000). The most frequently used constructs to classify the inhabitants of those interiors were age, social class, and family status.

Some authors have argued that preferences for styles in art and design are influenced by the social stratification of society, determined by factors such as people's age and education level and income (Bourdieu, 1979/1984; Holt, 1998 \& Vyncke, 2002). Davis studied the living room environment as a symbol of status and social judgment. According to Davis, living rooms reflect the differences between the inhabitants' tastes (Davis, 1955).

Sociologists and social anthropologists have examined the manifestation of social class and power relations in the society. In terms of interiors, they have investigated how the domestic interiors reflect the social structure (Bourdieu, 1984; Chapman, 1955; Davis, 1955; Douglas \& Isherwood, 1996; Halle, 1993). Research has shown that there are relationships between the physical features of the home and the social and demographic characteristics of the owners. For example, Laumann and House have shown that social attributes of a person are related to the individual's choice of the style used in their living rooms (Laumann and House, 1970).

On the other hand, as a result of his fieldwork in upper, middle, and working class neighbourhoods in New York, Halle found it difficult to create a relationship between class and taste. He suggested that it was a complex relationship. For example, he found that landscape pictures were popular in home decoration among all social classes. However, although they were popular among all classes, upper-class residents owned more expensive and original artwork, and they knew the artist's name. On the other hand, working class art owners rarely knew the artist of the artwork they had (Halle, 1993).

\subsection{Changing of preferences and socio-cultural trends from Zeitgeist point of view}

In addition to socio-demographic factors, a major socio-cultural factor influencing businesses and business decisions is changing consumer preferences. What were popular and fashionable 20 years ago may not be popular today or 10 years down the road. Different styles and priorities can undermine long, successful products and services. For example, a clothing company must constantly be aware of changing preferences when creating new products or it will quickly become outdated (Maria Mackinney, 2010).

The sociocultural trends of society change over time and are often influenced by environmental, technological and social means. In the past, different regions had their sets of sociocultural trends. While in some ways that is still the case, the invention of the Internet has led to a growth of interconnectedness, which has resulted in an increased number of sociocultural trends being observed worldwide (Sibel Seda Dazkır, 2013). The largest current sociocultural trend is the growth of connectivity through social media and telecommunications. More than ever before, ideas can be transferred instantaneously across nations. Ideas that used to be confined to certain hubs can now be anonymously displayed on the Internet and spread to the public.

\subsection{The concept of Zeitgeist}

The term Zeitgeist, frequently used by Heinrich Hübsch and his contemporaries in their texts, roughly means "the spirit of the age." Words that frequently replace Zeitgeist in translation and discussion are, for example, essence, fundamental, psyche, truth, 
origin (Tanju, 2010). However, as the meaning of the word cannot be defined precisely, it is used un-translated in its original German form. In its original language, Zeitgeist denotes "of our time" or "time spirit" and refers to the common virtual, intellectual and cultural environment of an age (New Dictionary of Cultural Literacy, 2005).

The German word Zeitgeist is often attributed to the philosopher Georg Hegel, but he never actually used the word. In his works such as Lectures on the Philosophy of History, he uses the phrase der Geist seiner Zeit (the spirit of his time). For example, "no man can surpass his own time, for the spirit of his time is also his spirit (Glenn Alexander Magee, 2011).

Hübsch's text dating from 1847 reveals significant clues about (Zeitgeist Hübsch's, 1992). Modernists envisaged a theory or a language based on the 19th century's notion of "the spirit of the age", called Zeitgeist by the Germans in reference to the belief that the spirit of the age could only have been expressed via art and architecture (Durmus, 2010).

Eero Saarinen defined The Zeitgeist, as it is the intellectual fashion or dominant school of thought that typifies and influences the culture of a particular period. For example, the Zeitgeist of modernism typified and influenced architecture, art, and fashion during much of the 20th century (Eero Saarinen, 2006). According to Fiona McLachla Zeitgeist defines how ideas, concepts, facts, events are absorbed by people's minds and translated into a culture. People can only see and interpret new information based on what they already know and what they already understand. New events are thus filtered through our cultural lenses and interpreted according to our beliefs, our political views, etc. (Fiona McLachla, 2012).

\subsection{The relation between Zeitgeist and interior design trends}

A trend is defined by a shift in behavior or mentality that influences a significant amount of people. This profound change in behavior is triggered by a small part of the population and starts to spread gradually until enough people finally give in and choose to adopt it as part of their lifestyle. This shift is often based on a strong concept and vision, initiated by the designers, based on predictions, color and material research (Maria Mackinney, 2010).

Trends and Zeitgeist seem to confirm what James Laver wrote that fashion is never arbitrary. It has its roots in the unconscious, the collective unconscious if you will, and the hopes and fears of a whole society are reflected in the design trends (James Laver, 1937).

A wide range of theorists has discussed the relation between Zeitgeist and trends. From Cecil Beaton who considered fashion trends to be reflections of the times as he wrote that Fashion is subtle and shifting expression of every age in (Cecil Beaton,1954); to German sociologist Ingrid Brenninkmeyer who described how fashion trends mirror the interplay of social, economic, political and religious influences. Brenninkmeyer argues that clothing is symbolic of the values and aspirations of an age; this relation between trends and times is dialectic (Brenninkmeyer, 1962). As Ernest Dichter explained that the two mutually inform one another, fashion expresses Zeitgeist, and in turn can influence it (Ernest Dichter, 1985).

According to Rosenberg, the idea of globalization no longer captured the spirit of the times; hence the age of globalization ended abruptly. While globalization was frequently regarded as the Zeitgeist of the 90 s, such concepts as sustainability and ecology can be taken under consideration within this scope (Rosenberg, 2005). This state of affairs seems to embody what catching the spirit of the age means. Durmus discussed in his study that architecture and interior design are part of a building process following what's on the agenda and depending on social and public needs. It is could be concluded that the Zeitgeist of society and culture can be found in its unique interior design (Durmus, 2012). Precisely at this point, we may find ourselves obliged to choose between the tradition and the future because Zeitgeist might be both representing the tradition and promising the future. This combination is the result of the interdependence of interior design and society.

\subsection{People preferences from the Zeitgeist point of view}

People preferences are moderated by cultural influences and may be largely defined by cultural agreements on 'what looks good, what materials are to be valued, what is worth aspiring towards and how aspirations can be reinforced with material goods (Dormer, $\mathrm{P}, 1990)$. It is not just these established conventions of taste, but also general trends and transient fashions, which may influence response. In particular, Zeitgeist contributes to how designs are interpreted and the extent to which they are accepted by society (Coates, D, 2003).

Fiona McLachla discussed the relation between people preferences and zeitgeist and explain that although individuals will always have preferences on colour and design styles, there is clearly an underlying zeitgeist born out of popular culture, which can have the effect of moderating the choices of the society at a given time. He clarified that Fashion in relation with interior design styles are undeniably influential, while some people will strive for the difference, some seek to conform, wishing to be 
seeing as in tune with fashion. Others are content to develop an identity independent of fads, or specifically to seek endurance (Fiona McLachla, 2012).

\section{Methodology}

A mixed method was used to investigate the thread to provide information from different sources throughout combining qualitative and quantitative methods.

A survey was conducted among 303 of high-educated respondents. Six sets of photographs for home interiors were selected, to represent three groups of styles, the first group included eclectic and retro styles (the most trendiest styles), the second group included modernism and contemporary styles (the styles that have been trendy a few years ago and have begun to flash out) and the third group included classic and ethnic styles (which considered out dated trends). The Internet was chosen as an auxiliary tool for the latest trends' prospection. From the popular interior design trends' forecasters sites to pages of distinct brands and creators, there is an enormous quantity of material that allowed defining the most prominence interior design trends at last five years. The photographs of these styles were standardized with respect to resolution ( $75 \mathrm{dpi}$ ), standard screen size (max. height $=15.5 \mathrm{~cm})$, to minimize possible style recognition effects. The validity of the use of color photographic representations of environments has now been well established in comparative methodological research (Stamps, 1990). SPSS 17 statistical package was used to analyze data. For richness of data and deeper insight into the influence of Zeitgeist on interior design style preferences, five personal interviews with Egyptian interior designers were a part of the research process.

\subsection{Research site}

Two research sites of this study are chosen to increase the diversity of perspectives by recruiting respondents from different cities with different characteristics. The first site is Cairo city, the capital of Egypt and the largest city in the Middle East. Cairo has long been a centre of the region's political and cultural life. Many international media, businesses, and organizations have regional headquarters in the city. The second city is Minya, the capital of Minya Governorate, one of the middle Upper Egypt governorates, which does not receive much attention, the two cities have different characteristics in terms of their population size, cultural environment, diversity and level of industrialization and urbanization.

\subsection{Classification of the interior design styles}

According to the popular interior design trends' forecasters (Li Edelkoort, 2015) and (Shelly Gerritsma, 2014), design trends 2015 include classic, retro and contemporary design ideas, traditional and new materials, fresh decorating colours, exotic motifs, artistic details. Modern interiors, where contemporary design ideas are combined with gilded antiques, velvet, and silk or carved wood accents are mixed with industrial metal details, look stylish, original and unique. Modern interior trends reflect the desire to establish a vivid and memorable way of creating bold and interesting works or living space that have personality. However, the re-popularized mid-century modern looks will continue to remain relevant, as well as contemporary and liquid designs inspired looks. Consequently, the Selected Interior design styles were classified into three groups according to their pertinence to the Zeitgeist, which is represented in the most popular trends at the last 5 years. The first group was (retro and eclectic styles) which are a combination between simplicity and complexity, and represent the latest interior design styles' trends, and the second group (modernism and contemporary styles) that tend to simplicity and represent the styles which have been popular before the last five years, while the third group have the most tendency to complexity and represent interior design trends that considered out-dated and weren't represent the zeitgeist, see Fig.1, 2. 


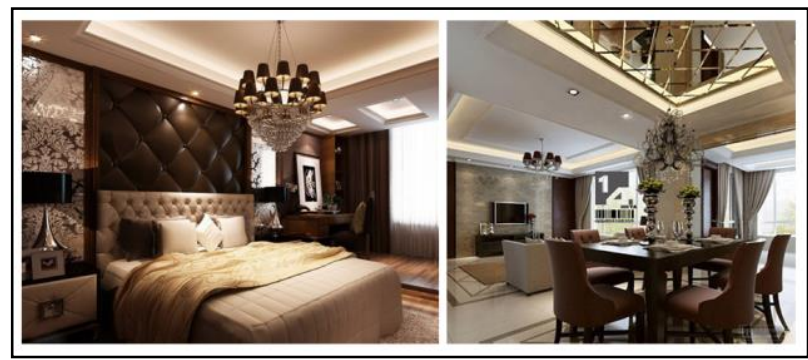

Eclectic Style

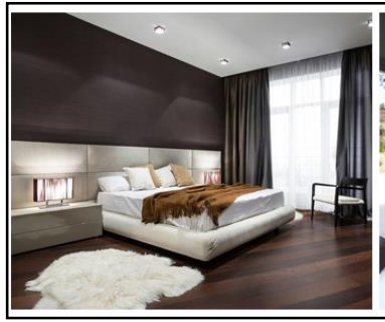

Modernism Style

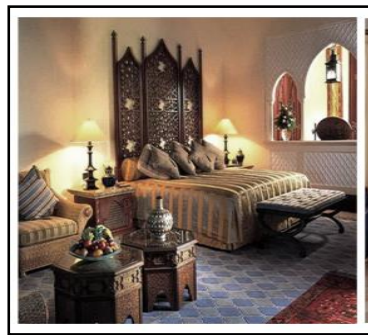

Ethnic Style

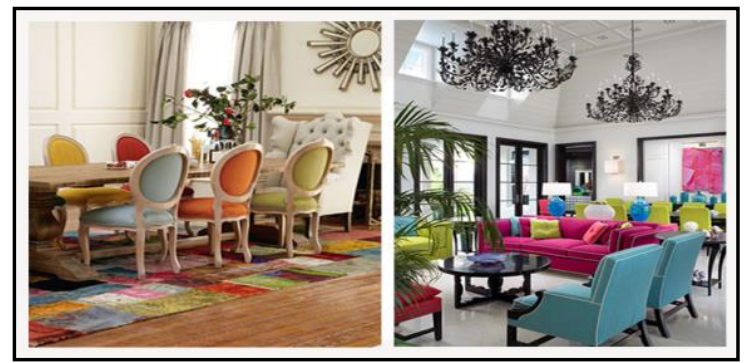

Retro Style

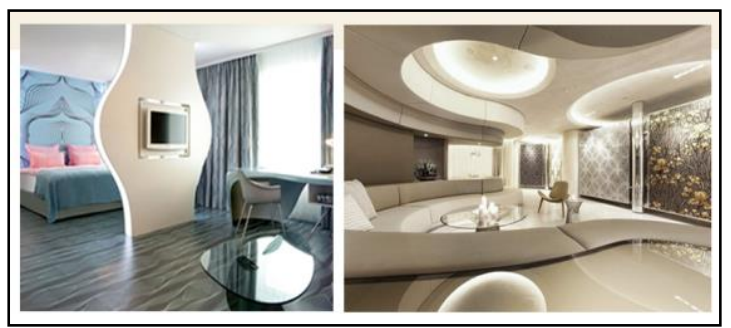

Contemporary

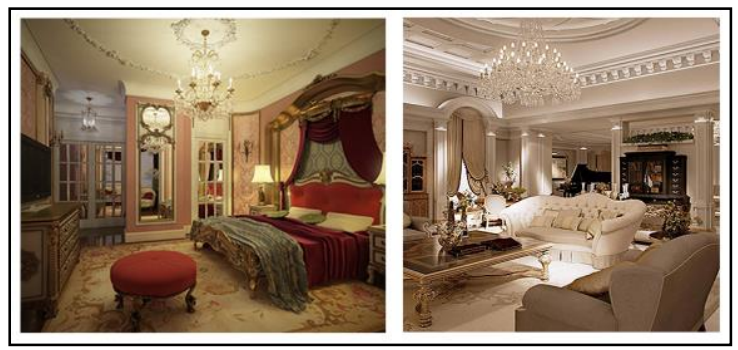

Classic Style

Fig. 1. The selected interior design styles

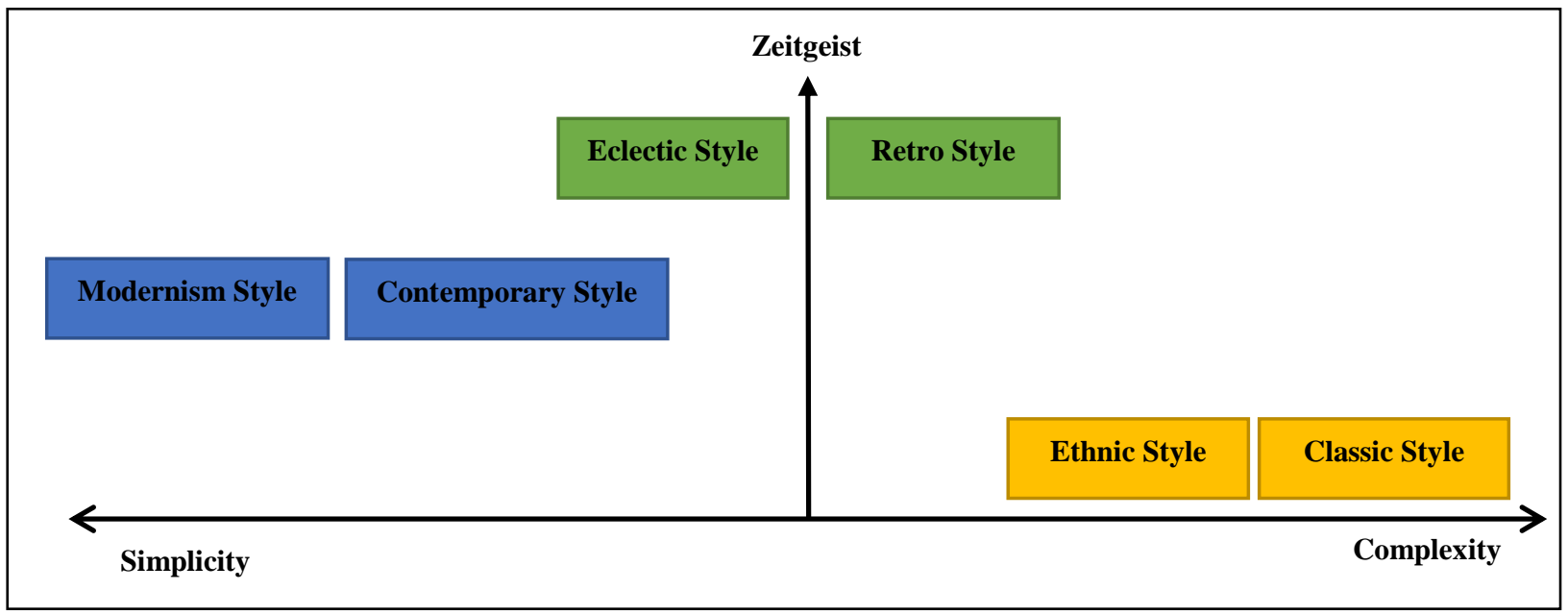

Fig.2. Classification of styles according to Zeitgeist 


\section{Findings}

A total of 303 usable responses were included in the data analyzed. $153(50.5 \%)$ of the respondents were female, and 150 $(49.5 \%)$ of them were male. The age of the respondents were classified into five groups, from 18 to 24 (41 respondents), from25 to 34 (101 respondents), from 35 to 44 (83 respondents), from 45 to 54 (59 respondents), and 55 or older (19 respondents). The respondents from Cairo city represented $54 \%$ (163 respondents) of the total respondent, and those from Minia city represented $46 \%$ (140 respondents). The high-educated category was chosen for this study. More than half of the respondents had less than $1200 \$$ monthly income, and about the third of them their monthly income ranged from $1200 \$$ to $3599 \$$. Whereas the category with the income that exceeds $3600 \$$ represented by $8.0 \%$ of the respondents, and about $19 \%$ didn't prefer to reply, see Table 1.

Table 1. Demographic characteristics of respondents

\begin{tabular}{|c|c|c|c|c|c|c|c|c|c|c|c|c|c|c|c|}
\hline & \multicolumn{2}{|c|}{ Gender } & \multicolumn{5}{|c|}{ Age } & \multicolumn{6}{|c|}{ Monthly Household Income } & \multicolumn{2}{|c|}{ City } \\
\hline & 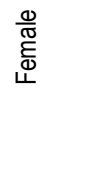 & $\frac{0}{\sum \pi}$ & 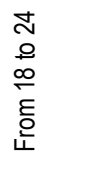 & 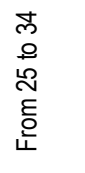 & 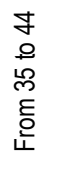 & 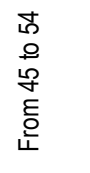 & 岕 & $\begin{array}{l}\text { A } \\
8 \\
0 \\
\wedge\end{array}$ & 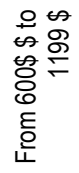 & 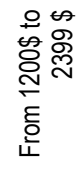 & 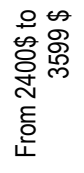 & $\begin{array}{l}\text { s } \\
\text { ठి } \\
\text { ठ্ల } \\
\text { v }\end{array}$ & 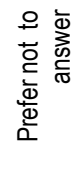 & 옳 & $\stackrel{\text { : }}{\stackrel{\text { I }}{\Sigma}}$ \\
\hline $\mathbf{N}$ & 153 & 150 & 41 & 101 & 83 & 59 & 19 & 72 & 84 & 45 & 18 & 24 & 57 & $\begin{array}{r}16 \\
3\end{array}$ & 140 \\
\hline$\%$ & $50.5 \%$ & $49.5 \%$ & $\begin{array}{r}13.5 \\
\%\end{array}$ & $33.6 \%$ & $28 \%$ & $19.7 \%$ & $5.2 \%$ & $24 \%$ & $28 \%$ & $15 \%$ & $6 \%$ & $8 \%$ & $19 \%$ & $\begin{array}{r}45 \\
\%\end{array}$ & $\begin{array}{l}46 \\
\%\end{array}$ \\
\hline
\end{tabular}

\subsection{General preferences for interior design styles}

The Analysis displayed that modernism style with weighted average (4.84) and eclectic style (4.15) were the most popular choice between the respondents. It was also found that the trendiest styles (eclectic and retro styles) with total average (3.66) came in the second rank after modernism and contemporary styles (3.97). However, classic and ethnic styles (5.72) had the last rank. Which indicated that the respondents' preferences for interior design styles neither tend to choose the latest nor the oldest trends, in general, they prefer the styles that were popular a few years ago, see Fig. 3.

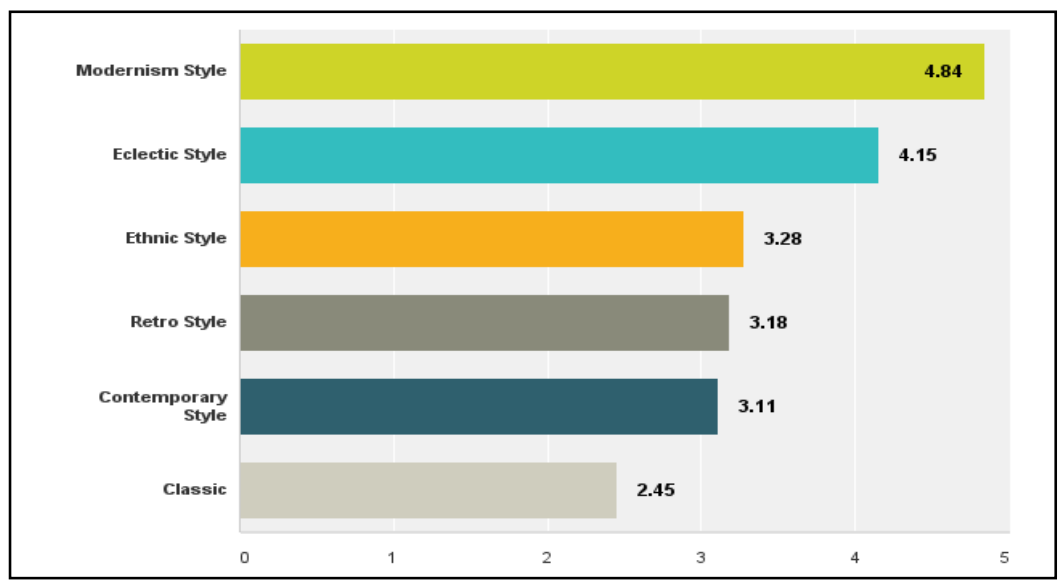

Fig. 3. General preferences for interior design styles 


\subsection{The relation between socio-demographic factors and interior design styles' preferences}

\subsubsection{Gender}

Results demonstrated the relationship between gender and interior design style preferences. Significant gender effects were found $(p=.05)$ in rating, males reported higher ratings than females throughout both modernism and contemporary styles, while females reported higher rating throughout the retro style. The results showed an overall tendency of female preference for the latest trends of styles (retro and eclectic) with total weighted average (3.8) than male with total average $(3,3)$, which indicated that females tend to be more influenced by the zeitgeist than male. For both male and female respondents, 'modernism and eclectic' was rated, as the most preferred styles, whereas classic was the least preferred one, see Fig. 4.

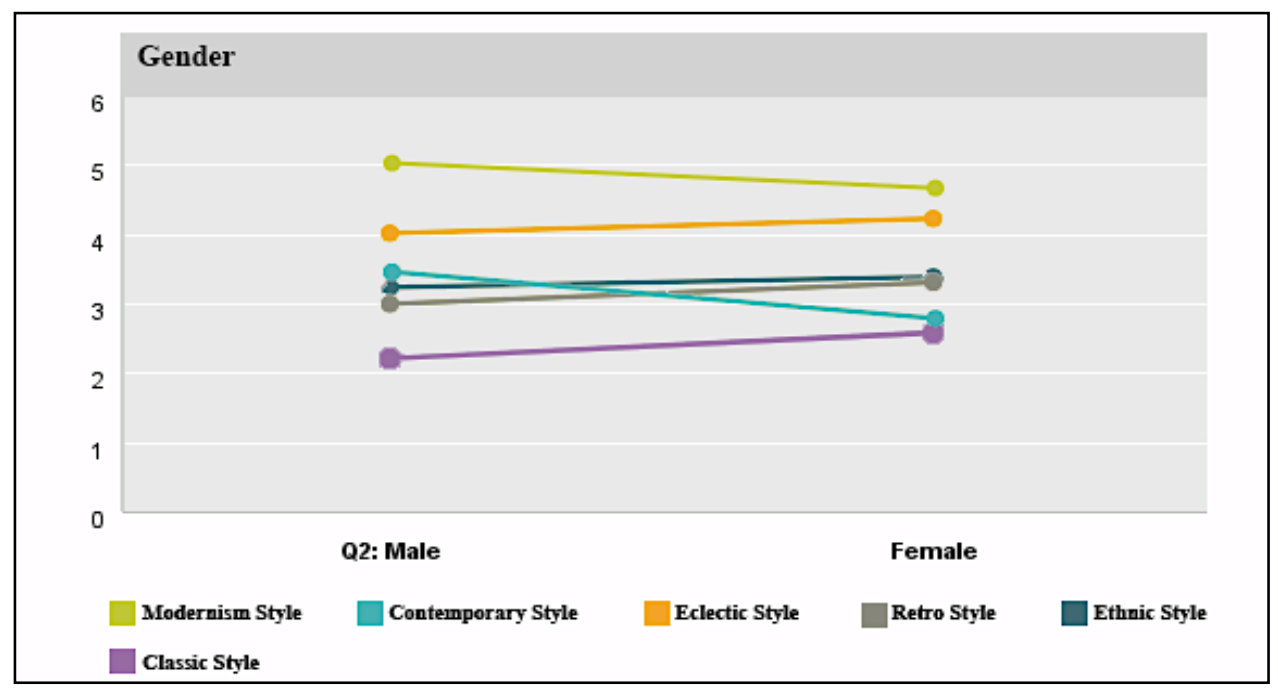

Fig. 4. The relation between gender and Interior design styles' preferences

\subsubsection{Age}

The relationship between age and preferences was investigated; modernism style was the most preferred choice for all age categories, whereas classic style was the least choice for the age categories less than 45 years old. The eclectic style was the most preferred at the age categories less than 34 and was least preferred at the age category more than 65 . On the other hand, the respondent with age from 18 to 24 rated the eclectic style (4.13) and retro style (3.75), which represent the trendiest styles at the second rank, whereas they rated Classic style (2.2) at the last rank. That indicates that this category of age tends to be more followed to the latest trends and more influenced by Zeitgeist. The results also showed that the respondent with age more than 55 reported high rating throughout the ethnic and classic styles that didn't represent Zeitgeist see Fig. 5.

\subsubsection{Household income}

The results suggest that household income had an influence on the preference, as shown in Fig.6, preference of styles significantly different between the respondents with income less than $3600 \$$ and those with income more than $3600 \$$. The respondents with the higher income reported high rates to the classic style with total weighted average (4.92). However, they reported relatively low rates to modernism style (3.84) and contemporary style (2.45). The explanation that concluded from the interviews with interior designers that this income category is content to develop an identity independent of fads, or specifically seek difference. On the other hand, eclectic and retro styles had a high total average (4.31) between the income category less than 600 \$。 that considered the middle part of the middle class in Egypt. That may be an indication that this category seeks to conform to the latest trends and wish to be seeing as in tune with fashion McLachlan, F. (2013). The results also showed that modernism style is the most preferred amongst the categories less than 3600 USD whereas the eclectic style had the second 
rank of preference and had a consensus among all income categories, which means that all categories accepted this trendy style.

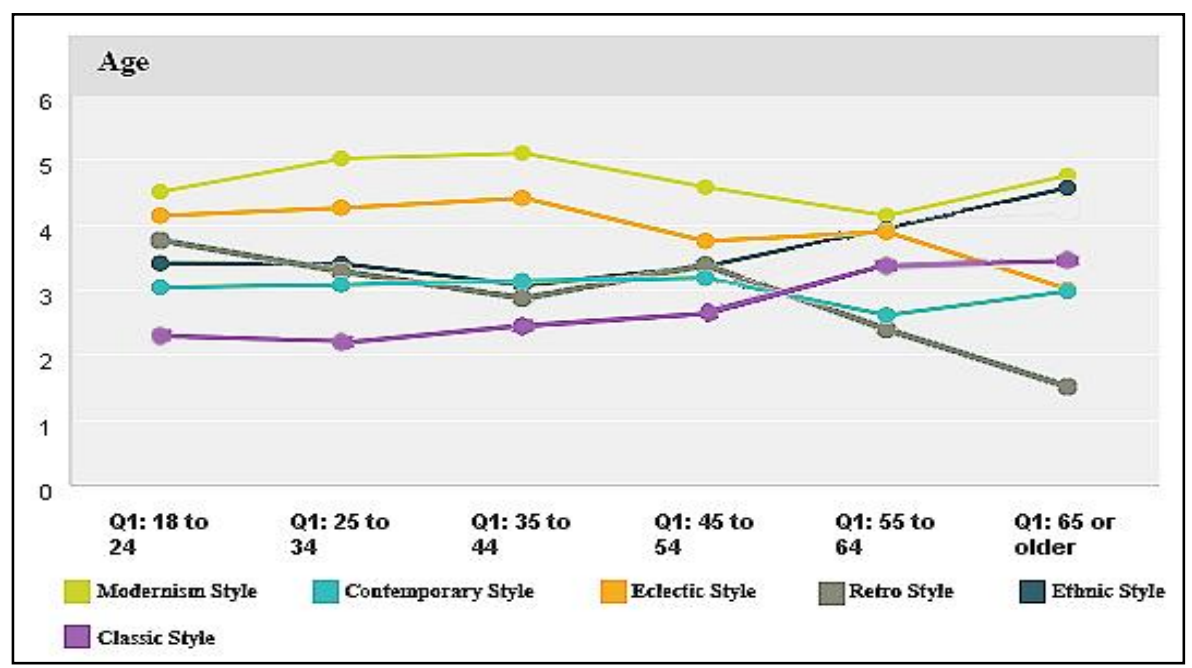

Fig. 5. The relationship between age and interior design styles' preferences

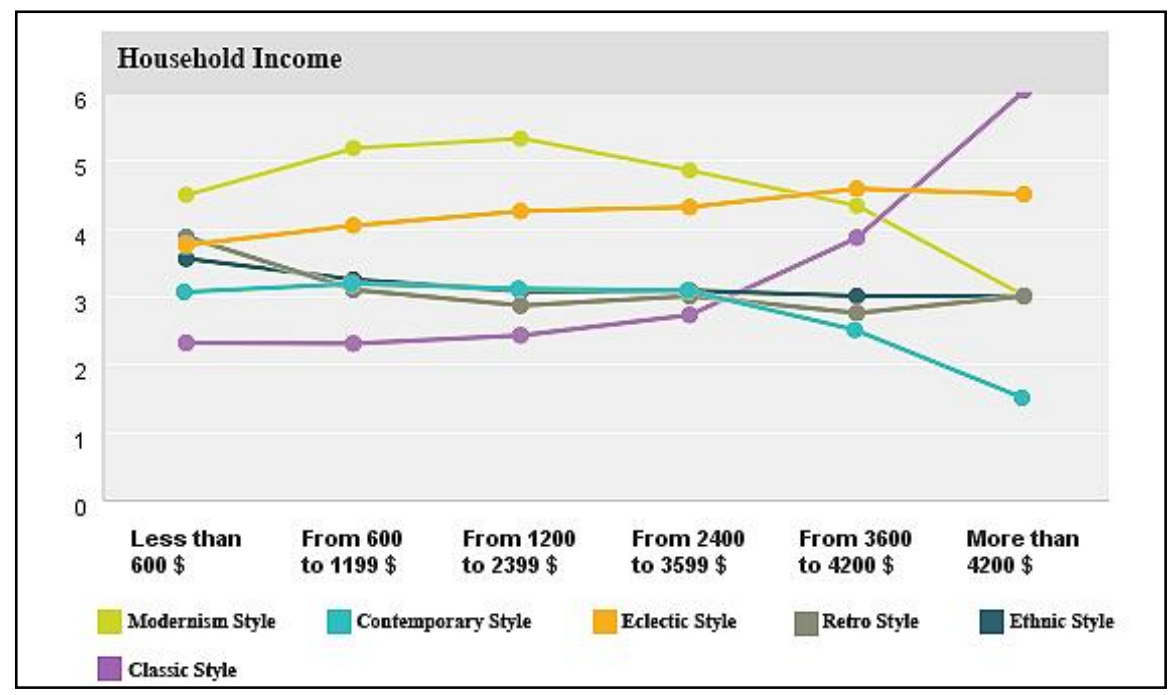

Fig. 6. The relationship between household income and interior design styles' preferences

\subsubsection{City}

The results revealed that city had no significant influence on preference; Fig.7 shows the mean preference values for each city for each style. For Cairo respondents, (modernism 4.86, contemporary 3.22, eclectic 4.11, retro 3.14, ethnic 3.29, classic 2.62). For Minia respondents, (modernism 4.74, contemporary 3.00, eclectic 4.21, retro 3.25, ethnic 3.23, classic 2.41). The small effect for the city by style preference indicated by the nearly horizontal lines, which connecting the two cities for respondents in three styles, modernism, eclectic and classic. 


\subsubsection{Major}

The relationship between the major and the six styles preferences was investigated; the respondents were classified into two groups, interior design and fine arts group and the other majors group. The results revealed that the modernism and eclectic styles were the most preferred for the two groups. On the other hand statistically significant difference was found in preference between the two groups towards retro style, which considered the most colorful and trendiest style. The results showed an overall tendency of "interior design and fine arts" group preference for retro style (3.81), which had the third rank of their preferences. Whereas "others" group did not prefer retro style (2.74), and it had the fifth rank of their preferences. This means that interior design and art group was more influenced by this colorful trend and accepted for it than the other majors, may be for the nature of fine arts major, see Fig. 8.

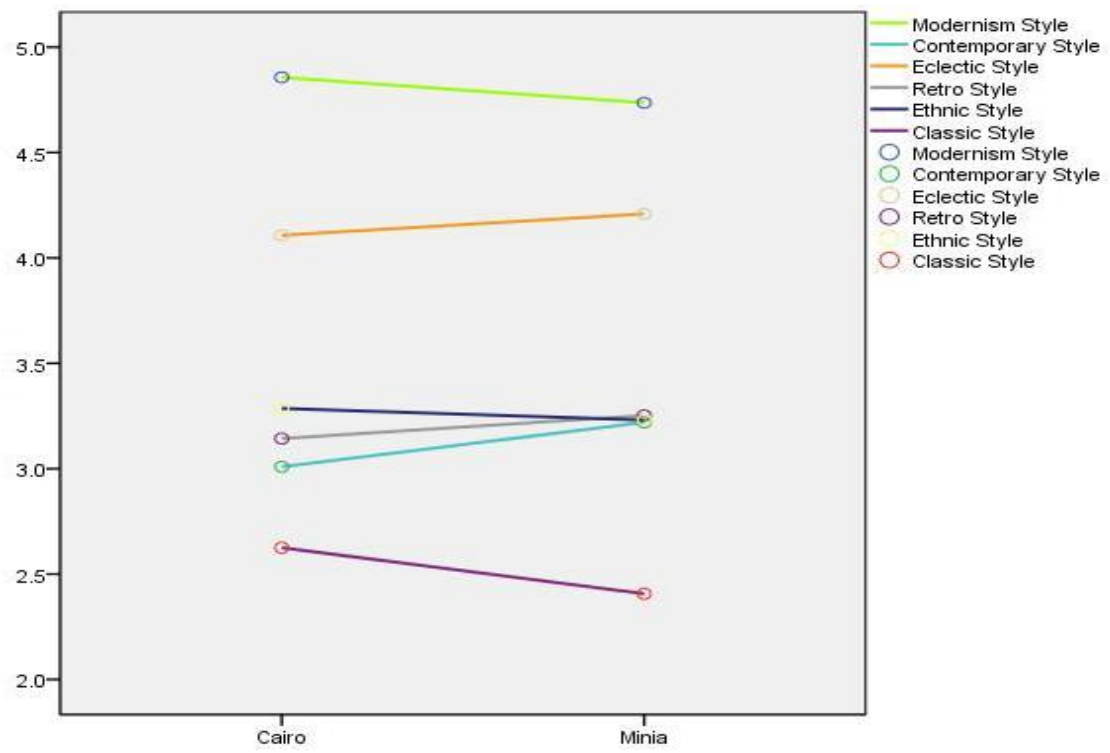

Fig.7. The relation between city and styles' preferences

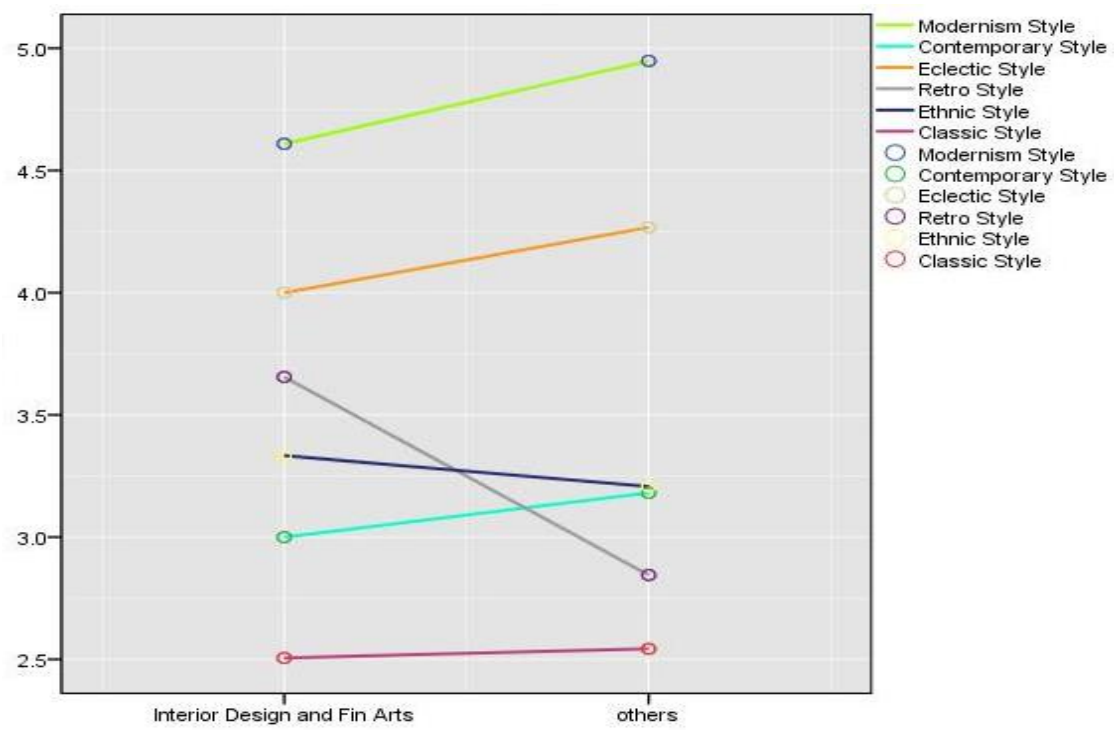

Fig.8. The relation between major and styles preference 


\section{Discussion}

Previous research has demonstrated the presence of relationships between socio-demographic variables and design preferences for styles (Lawrence, 1987; Eleb-Vidal (1983); Bourdieu, 1979/1984; Holt, 1998). The previous literature has also suggested that people's preferences for interior design styles are influenced by social distinctions, based on education level and age bracket and social class (Bourdieu, 1984; Chapman, 1955; Davis, 1955; Douglas \& Isherwood, 1996; Halle, 1993). In this study, we have argued more precisely socio - demographic factors (gender, age, income, major and city) that affect the Egyptians' preferences for interior design styles, and have discussed to what extent do these preferences reflect Zeitgeist.

In a quantitative study with over 300 people from 2 Cities: Cairo and Minia, by carried out a questionnaire of six groups of photographs for home interiors to measure the Egyptians' response according to satisfaction scales. The study has demonstrated how design preferences relate to people's socio- demographic factor ، and has analyzed the results from the point view of Zeitgeist.

The results showed that modernism style was the most preferred style for all demographic groups, and the eclectic style had the second rank of preference. However, the classic design had the last rank. That was an indication that the respondent preferences neither tend to choose the latest nor the oldest trends, in general, they preferred the styles that were popular from a few years ago represented by modernism style. Whereas most respondents didn't prefer the outdated styles, that was represented by classic and ethnic styles. That means that Zeitgeist in interior design needs more time to influence Egyptian preferences. The results of the interior designers' interviews suggested that this returns for being interior design field relatively an emerging field in Egypt and most of the people didn't recognize the difference between styles. They depend almost on the visual experiments that they live, and they usually see.

The study is also supporting literature that the interior of the home enables people to express themselves in terms of their group identities (As Eleb-Vidal, 1983). This study investigated the relationship between four demographic factors (gender, age, income and major) and interior design preferences from the point view of Zeitgeist. Interestingly, that the gender and major influenced the respondent preferences as females and interior design and fine arts major preferred retro style that considered the trendiest and colorful trend. Furthermore, the results indicated that the smaller the age, the more influence they have by the new trends in interior design, which was reflected clearly in the choices of the trendiest styles between the smaller age. However, the older categories were stuck by the classic style. Additionally, the data also revealed that The income play a role in the interior design preferences among the respondents, as the income category more than $3600 \$$ preferred the classic and eclectic styles than the other categories. On the other hand, the income category less than $600 \$$ preferred the retro and the modernism styles. Which support the idea that Fashion in relation with interior design styles, are undeniably influential while some people will strive for the difference, some seek to conform, wishing to be seeing as in tune with fashion. Others are content to develop an identity independent of fads, or specifically to seek endurance (McLachlan, F. 2013).

No significant differences were found in the preferences related to the city. The interior design interviews showed that this is a result of the fact that most people in Egypt update their knowledge by the internet, social media and T.V shows, series and movies, which supported the idea that the sociocultural trends of society are often influenced by technological and social means. In the past, different regions had their sets of sociocultural trends. While in some ways nowadays, the invention of the Internet has led to a growth of interconnectedness, which has resulted in an increased number of sociocultural trends being observed worldwide (Sibel Seda Dazkır, 2013).

As an effort to combine research and practice, we attempted to provide useful information for interior design practitioners by examining people's interior design style preferences.

The findings of this study could provide a foundation for the future studies on the Egyptian interior design preferences. It was suggested that further research studies with more diverse groups in diverse markets could be conducted, to understand better the influence of Zeitgeist on the interior design industry.

This study could be repeated in different cities to acquire more respondent perspectives. The relationship between another demographic characteristics of the respondents (such as their education level and social class) could be investigated.

\section{Acknowledgements}

The author would like to thank, Ashraf Bassyouni, for his support and helpful suggestions on this research, and the interior designers who participated in the study for their help in collecting the qualitative data. 


\section{References}

Beaton, C. (1954). The Glass of Fashion. Doubleday. Chicago.

Bourdieu, P. (1984). Distinction: A social critique of the judgement of taste. Harvard University Press.

Coates, D Watches. (2003). Tell more than time: Product design, information and the quest for elegance. London, UK: McGraw-Hill

Dichter, E. (1985). Why we dress the way we do. The psychology of fashion, 29-38.

Dormer, P. (1990). The meanings of modern design: Towards the twenty first century. London, UK: Thames \& Hudson.

Durmus, S. (2012). Change and Transformation in Architecture: On the Concept of Zeitgeist. Global Built Environment Review, 8(1).

Eero Saarinen. (2006). Shaping the Future. Yale University Press.

Glenn Alexander Magee. (2011). The Hegel Dictionary, Continuum International Publishing Group, p. 262, ISBN 9781847065919

Hall, T. \& Hubbard, P. (1996). The entrepreneurial city: New urban politics, new urban geographies. Progress in human geography, 20(2), 153-1

Halle, M., \& Marantz, A. (1993). Distributed morphology and the pieces of inflection.

Hübsch, H. (1992). The Differing Views of Architectural Style In Relation to the Present Time: In What Style Should We Build?. USA: The Getty Centre.

Laumann, E. O., \& House, J. S. (1970). Living room styles and social attributes: The patterning of material artefacts in a modern urban community. Sociology and Social Research, 54(3), 321-342.

Lawrence, R. J. (1987). What makes a house a home? Environment and Behaviour, 19(2), 154-168. Retrieved from

http://eab.sagepub.com/content/19/2/154.abstract

Maria Mackinney. (2010). On The Nature of Trends: A Study of Trend Mechanisms in Contemporary Fashion

Brenninkmeyer. (1962). The Glass of Fashion, 337.

McLachlan, F. (2013). Architectural colour in the professional palette. New York, NY: Routledge.

New Dictionary of Cultural Literacy. (2005). New Dictionary of Cultural Literacy, Zeitgeist.

Saarinen, E., Pelkonen, E. L., \& Albrecht, D. (2006). Eero Saarinen: Shaping the future. Yale University Press.

Stamps III, A. E. (1990). Use of photographs to simulate environments: A meta-analysis. Perceptual and Motor Skills, 71(3), 907-9. Retrieved from http://www.amsciepub.com/doi/abs/10.2466/pms.1990.71.3.907

Tanju, B., (2010). Mimarlık Düşüncesi Tarihi, MIM6602 Postgraduate Course Notes. Yıldız Technical University, unpublished.

Wilson, D. B., Gallagher, C. A., \& MacKenzie, D. L. (2010). A meta-analysis of corrections-based education, vocation, and work programs for adult offenders. Journal of Research in Crime and Delinquency, 37(4), 347-368. 